is essential. Competition is the antithesis of care.

The door is wide open. Never has the standing of the political class been lower in the public's estimation. The commentariat is loud in its support for new blood in politics.

There are no excuses. This is the right time to achieve the future that will benefit the patients. Let's have a healthcare professional standing in every constituency.

\section{Steven Ford,}

Haydon Bridge NE47 6HJ.

E-mail: mail@stevenford.co.uk

\section{REFERENCE}

1. Ford SD. How to become an MP. BMJ 2007; 335(7624): 826.

DOI: 10.3399/bjgp09X454197

\section{Vertical versus horizontal integration}

I was impressed by Martin Marshall's clearly thought out analysis of the role of general practice in a modern health system, ${ }^{1}$ although one might debate the detail. For instance, personally I regret the loss of 24-hour responsibility and only reluctantly accept the strength of his argument in relation to this. However, Marshall's three core principles might be a useful basis for looking at many current problems - and one in particular swine flu.

The three principles, paraphrased and abbreviated, are that GPs are: medical generalists who are up to date with the evidence; committed to whole person care; and advocates on behalf of their patients.

For swine flu, a vertical approach is encouraged in which services are provided in a uniquely different way for one condition of supposedly over-riding importance. This is unlikely to work well in primary care. Many patients who think they have swine flu have nothing of the sort and are disproportionately or inappropriately worried. A few who are discouraged from consulting face-to-face will turn out to have meningococcal meningitis and suffer a worse outcome because of the delay in diagnosis. Guidelines and policy have very little evidence underpinning them, and where there is evidence or lack of it this information is not being made available to GPs or to the public. Care of individual patients is taking second place to flattening the pandemic curve and we are doing our patients a disservice if we accept this ordering of priorities without question.

It is, perhaps, not surprising that politicians, the media, and the public have a poor grasp on science and it may not be news to us that many scientists and medics don't appreciate the nature of general practice. However, I find it disappointing that our GP leaders seem, largely without protest, to accept the official policy that reflects a poor understanding of both.

Wilfrid Treasure,

Muirhouse Medical Group,

1 Muirhouse Avenue, Edinburgh.

E-mail: wilfrid.treasure@/othian.scot.nhs.uk

\section{REFERENCE}

1. Marshall, M. Practice, politics, and possibilities. $\mathrm{Br} J$ Gen Pract 2009; 59(565): 605-612.

DOI: 10.3399/bjgp09X454205

\section{Sickness certification}

The paper from Wynne-Jones et al on sickness certification rates is timely and adds to the evidence on this field in the UK. I note, however, a couple of minor errors with reference to the research we undertook a few years ago in the UK on the same topic. ${ }^{1}$ We also collected data on actual sicknotes not, as stated in the discussion, the use of incapacity reports as a proxy. We were able to track consecutive and separate periods of sickness absence from an anonymised database of over 13000 sicknotes of around 7000 patients in a 1-year prospective sicknote survey across 10 practices. We were looking for data on risk factors that increased the risk of entering longer-term absence and incapacity, but used sicknote data to do that. The other citation of our work ${ }^{2}$ relates to a secondary analysis of our database where we demonstrated the differential risk of longer-term absence depending on gender interaction in the consultation and while European data (as the UK is in Europe), it was our 2004 paper that was the first to report the preponderance of mild mental health problems over musculoskeletal disorders as the greatest cause of sickness absence. I presume this is a drafting error, but perhaps it is important to clarify that this paper is further evidence on UK certification practice from records, not the first ever. However, a common problem with our databases is that it is not possible to distinguish those in employment from those on benefit using either of these methods. It is to be hoped that the recent NICE guidance (that recommends this) and the forthcoming introduction of the electronic fit for work note due to replace the MED3 and 5 in 2010, promotes more systematic recording of patients' occupation, work capacity, and role in records, particularly when capacity for work is a subject of the consultation.

\section{Mark Gabbay,}

University of Liverpool, Whelan Building,

Quadrangle, Brownlow Hill,

Liverpool L69 3GB.

E-mail:m.gabbay@nt/world.com

\section{REFERENCES}

1. Shiels C, Gabbay MB, Ford FM. Patient factors associated with duration of certified sickness absence and transition to long-term incapacity. Br J Gen Pract 2004; 54(499): 86-91.

2. Shiels $\mathrm{C}$, Gabbay M. The influence of GP and patient gender interaction on the duration of certified sickness absence. Fam Pract 2006; 23(2): 246-252.

3. NHS Evidence. Management of long-term sickness absence and incapacity for work. NICE 2009. http://www.library.nhs.uk/MENTALHEALTH/ViewRes ource.aspx?resID=310240 (accessed 11 Aug 2009).

DOI: 10.3399/bjgp09X454214

\section{Correction}

In the August issue of the BJGP we incorrectly published the order of authors, it should be as follows:

Brittain D, Jones M. Music in the waiting room. $\mathrm{Br} J$ Gen Pract 2009; 59(565): 613-614.

We apologise for this errror.

DOI: 10.3399/bjgp09X454223 